\title{
SeIS PROpósitos COMUNICATIVOS DEL DISCURSO DEL EDITOR DE LAS REVISTAS CIENTÍFICAS
}

\author{
(Six communicative purposes in the discourse \\ of editors of scientific journal)
}
(Seis propósitos comunicativos no discurso de editores de revistas científicas)

Omar SABAJ

(Universidad de La Serena; Prodicyt, Centro de investigación)

Cristian González

(Pontificia Universidad Católica de Valparaíso;

Prodicyt, Centro de investigación)

Resumen: El presente trabajo se centra en la identificación y caracterización de los propósitos comunicativos del discurso del editor en las revistas científicas, al que hemos denominado 'género editorial', independiente de las etiquetas que le asignan los usuarios en las revistas. Un estudio reciente de Sabaj, Matsuda y Fuentes (2010), acerca de las características de las revistas científicas en el ámbito nacional, advierte sobre la gran diversidad de géneros en los que se produce y comunica la ciencia. El concepto de género se define a partir de los propósitos comunicativos utilizados en la comunidad discursiva que los produce. El objetivo de este estudio fue identificar los propósitos comunicativos del discurso del editor de las revistas científicas chilenas. Si bien estos textos tienen características comunes en todas las revistas (solo aparecen una vez y siempre al comienzo del número), sus propósitos comunicativos particulares no ban sido descritos en detalle. En un análisis previo de la producción científica en Chile, se determinó que, de 14.460 datos analizados, un 10,7\%, esto es, 1.552, corresponden al discurso del editor. A partir del uso de un libro de códigos, se identificaron seis propósitos comunicativos de los textos que constituyen el género editorial de las revistas científicas. Los datos muestran que los editoriales de las revistas científicas cumplen con los siguientes seis propósitos comunicativos: 1) Agradecimientos, 2) Opiniones, 3) Discurso de la revista sobre la revista, 4) Homenajes, 5) Información sobre eventos de la comunidad y 6) Presentación de los artículos del número. Los resultados permiten concluir, además, que tanto los propósitos comunicativos como las etiquetas (clases textuales) que se usan para denominar al discurso del editor, varían a través de las áreas de la ciencia. Los 
resultados de esta investigación son una evidencia útil para aquellos interesados en el análisis del discurso en contextos científicos, y en las prácticas de difusión de la ciencia en general. Palabras-claves: Géneros discursivos, Género editorial, Revistas Científicas, Propósitos comunicativos.

Abstract: The present article focuses on the identification and characterization of the communicative purposes of the editor's discourse of scientific journals, which we have called "editorial genre" independent of the labels given to them by the users of the journals. A recent study done by Sabaj, Matsuda and Fuentes (2010) on the characteristics of scientific journals indicates the wide diversity of genres in which science is produced and communicated. The reasons of the existence of these genres are the communicative purposes they convey in the discursive community that produces and uses them. The objective of this study was to identify these communicative purposes in the discourse of the editors of Chilean scientific journals. Although these texts have characteristics in common with all journals (they only appear once and always at the beginning of the edition), their individual communicative purposes have not been described in detail. In a previous analysis of the scientific production in Chile, it was determined that, of 14,460 data entries analyzed, 10.7\% (that is to say 1,552) correspond to the editor's discourse. Using a book of codes, six communicative purposes were identified in the texts that constitute the editorial genre in scientific journals. The data shows that the editorials in scientific journals can be organized within the following six communicative purposes: 1) Thanks, 2) Opinions, 3) Discourse from the journal about the journal, 4) Homages, 5) Information about community events 6) Presentation of the articles that appear in the edition. The results allow us to conclude that the communicative purposes as well as the labels (textual classes) that are used to determine the editor's discourse vary throughout the different scientific areas. The results of this research are useful for those who are interested in the analysis of discourse in scientific contexts and in the dissemination practices in the scientific community at large.

Key-words: Discursive genres, editorial genre, scientific journals, communicative purposes.

Resumo: $O$ presente estudo tem como objetivo identificar e caracterizar os propósitos comunicativos do discurso do editor nas revistas científicas, denominado 'gênero editorial', independente dos rótulos que lhe são atribuidos nas revistas. Num estudo recente de Sabaj, Matsuda e Fontes (2010), com respeito às características das revistas científicas no âmbito chileno, observa-se uma grande diversidade de gêneros na produção e comunicação científica. O conceito de gênero se define a partir dos propósitos comunicativos utilizados na comunidade discursiva que os produz. O objetivo deste estudo foi identificar os propósitos comunicativos do discurso do editor das revistas científicas chilenas. Embora estes textos tenham características comuns em todas as revistas (só aparecem uma vez e sempre no início da revista), seus propósitos comunicativos particulares não têm sido descritos em detalhes. Numa análise prévia da produção científica do Chile, foi observado que, de 14.460 dados 
analisados, cerca de 10\%, correspondem ao discurso do editor. A partir de um livro de códigos, foram identificados seis propósitos comunicativos dos textos que compõem o gênero editorial das revistas científicas. Assim, os editoriais das revistas científicas cumprem com seis propósitos comunicativos: 1) Agradecimentos, 2) Opiniões, 3) Discursos da revista sobre a revista, 4) Homenagens, 5) Informações sobre eventos da comunidade e 6) Apresentações dos artigos daquela edição. Os resultados permitem concluir, ainda, que tanto os propósitos comunicativos como os rótulos (classes textuais) que são utilizados para denominar o discurso do editor, variam através das áreas da ciência.

Palavras chaves: Gêneros discursivos, Gênero editorial, Revistas Científicas, Propósitos comunicativos.

\section{INTRODUCCIÓN}

Para nadie es sorpresa que, en los últimos años, el interés por publicar en revistas indexadas ha aumentado en forma exponencial. Dado el carácter estratégico de las publicaciones científicas (Valderrama, 2001) para los distintos actores involucrados en la investigación, éstas se han transformado en una suerte de carta de presentación, de prestigio y estatus. La comunicación científica tiene diversas formas de expresión, siendo su principal producto, los denominados artículos científicos. Por su relevancia, el estudio de estos textos ha acaparado la atención de los principales trabajos en esta área, dejando relegados otros géneros o prácticas comunes en el discurso científico. Sabaj, Matsuda y Fuentes (2010) reportan que solo el $70 \%$ de los textos incluidos en revistas científicas chilenas, entre los años 2000 y 2008, corresponden a artículos de investigación científica. El 30\% restante correspondería a una gran cantidad de diversas clases textuales que cumplen diferentes funciones en las revistas, y en la comunidad discursiva en la que esa revista se inserta. Dentro de los géneros que circulan en el discurso científico, específicamente, en las revistas científicas, el discurso del editor, analizado aquí como género editorial, constituye uno de esos géneros que han sido relegados del estudio. Este género, que según los autores (Sabaj Matsuda \& Fuentes, 2010) aparece en un 90\% de las 72 revistas indagadas, no ha sido descrito en forma detallada en contextos de circulación científica. La relevancia del estudio del discurso del editor se basa en que éste es una ventana privilegiada para analizar cómo circula el discurso oficial sobre la práctica científica. Este conocimiento es de gran utilidad para los principales actores involucrados en esta práctica: editores, autores, evaluadores y lectores. En este contexto, el objetivo de esta investigación es identificar los propósitos comunicativos del discurso 
del editor en las revistas científicas. El artículo está organizado en las siguientes secciones. Presentamos, en primer lugar, una discusión teórica, respecto de la noción de 'propósito comunicativo', y algunas características generales del género editorial en contextos científicos. Mostramos luego los procedimientos metodológicos seguidos en la investigación. En la última parte, exponemos los resultados y una discusión, para finalizar con las principales conclusiones del trabajo.

\section{Propósito comunicativo: FUnCión teXtual y FinAlidad}

Como siempre, tanto en el análisis del discurso como en la lingüística general, existe un uso extendido de la terminología. Como bien sabemos, la utilización de tal o cual terminología es una forma de adherir a cierto enfoque. Sin embargo, a veces las discusiones terminológicas solo ayudan a confundir o son sesgadas, y más que aportar a una discusión clara, solo buscan resaltar más las diferencias específicas que los rasgos comunes que unen a distintos conceptos. Es esto justamente lo que creemos sucede con el uso de términos como propósitos comunicativos, función textual o finalidad, que si bien provienen de marcos teóricos distintos, apuntan a un fenómeno relativamente similar.

Así, el término propósito comunicativo es utilizado con acepciones muy disímiles. Conscientes de esto, consideramos que para adentrarnos en la identificación de los propósitos comunicativos de un género particular, es necesario, primero, aclarar qué entendemos por propósito comunicativo. Para ello, realizaremos una revisión, analizando términos similares como 'función textual', 'tipo de texto' y 'clase textual'.

En términos generales, el propósito comunicativo es la función que cumple un género al interior de una comunidad discursiva. Sin embargo, los textos a menudo no revelan de forma explícita la intención o el fin con el que se utilizan; más aún si consideramos que muchas veces los mensajes son indirectos, las circunstancias en que son emitidos no contribuyen a su comprensión, y el conocimiento compartido entre emisor y receptor no es equivalente.

Por lo anterior, en algunos casos, la tarea de reconstruir la intención comunicativa del hablante por parte del receptor se hace extremadamente 
dificultosa. Para ello, resulta necesario que el emisor considere aspectos de la situación comunicativa que son relevantes para que el lector pueda interpretar adecuadamente su intención comunicativa, y así lograr una comunicación efectiva.

Para Brinker (1988), la función textual corresponde al propósito comunicativo del hablante, expresado en el texto con determinados recursos, válidos convencionalmente, es decir, reconocidos como tales por una comunidad específica. Para este autor, la función de un texto es el propósito del emisor, que debe reconocer el receptor. Dicho de otra forma, es la indicación del emisor al receptor acerca de cómo éste debe entender el texto, por ejemplo, como un agradecimiento o una opinión.

Desde esta perspectiva, el acto ilocutivo se reconoce como la acción que se acomete al realizar una expresión; en este sentido, el propósito comunicativo se refiere al tipo de contacto expresado por el productor frente al interlocutor. Valga aquí remarcar la diferencia entre el propósito comunicativo y el "propósito verdadero" del productor textual. El propósito verdadero, la "intención secreta", puede por cierto coincidir con el propósito comunicativo, pero esto no es obligatorio, y por lo demás, es imposible de determinar.

También es preciso diferenciar el propósito comunicativo del efecto que el texto ejerce efectivamente sobre el receptor. El efecto textual no está convencionalizado, esté premeditado o no. Por el contrario, el propósito comunicativo es más bien la función comunicativa general de un texto, la que no se logra por medio de un listado de actos ilocutivos de las oraciones individuales. Las oraciones, integradas en la totalidad "texto", no poseerían una cualidad accional directa; solo podría determinarse para ellas funciones específicas internas al texto (Ciapuscio 2004 y 2005). En estos mismos términos, van Dijk (1978) propone que es posible determinar un "acto de habla global" que se ejecuta por una secuencia de micro-actos, posiblemente diferentes.

En un nivel de abstracción mayor, la noción de propósito comunicativo se asocia también a lo que Charaudeau (2006) denomina finalidad de un texto. El autor sugiere que determinar la finalidad de un texto equivale a preguntarse: ¿estamos aquí para decir o hacer qué? El autor (Charaudeau 2006) describe una tipología de los tipos de finalidad, fundamentales en cualquier texto: un "hacer saber" (o información), un "hacer pensar" (persuasión), un "hacer hacer" (o incitación), un "hacer saber hacer" (o instrucción). Se asume que distintos tipos de finalidad pueden co-existir 
en una misma situación de comunicación. Para definir la finalidad, se debe caracterizar la identidad de los protagonistas del intercambio, en términos de "clase categorial" (año, sexo, medio social). La finalidad, además, depende del "estatus" (administrativo, profesional) y de la "relación de poder" e, incluso, de ciertos "rasgos psicológicos" de los participantes.

Muy cercana a esta propuesta, en el Genre Analysis (Swales 1990 y 2004), se entiende que una característica esencial de los géneros es el propósito comunicativo. Esta definición, más cercana a aquella de Brinker (1998), es la que utilizamos en la presente investigación:

"A strong thread that binds the three key elements together is that of communicative purpose. It is communicative purpose that drives the language activities of the discourse community; it is communicative purpose that is the prototypical criterion for genre identity [...]" (Swales 1990:10).

Tal como indica Swales (1990: 46), "genres are communicatives vehicles for the achievement of goals". Dado el enfoque comunicativo que se adopta en este marco teórico, en el cual se entiende que los géneros existen en función de los propósitos que cumplen al interior de una comunidad discursiva, se sostiene del Genre Analysis que es una lingüística funcional.

Cada evento comunicativo o texto posee un propósito que lo origina y que, al mismo tiempo, junto a otras variables, permite identificarlo como un ejemplar de un género discursivo determinado (Askehave \& Swales, 2001). Este propósito es denominado por algunos autores como propósito comunicativo del género o macro propósito (Swales 1990, 2004; Bhatia 1993, 1997, 2002; Dudley-Evans 1994). El propósito comunicativo es concebido como el objetivo último para el cual un género discursivo es utilizado en un intercambio comunicativo y se constituye como el rasgo esencial para su identificación.

\section{LOS EDITORIALES DE LAS REVISTAS CIENTÍFICAS: UNA DEFINICIÓN GENERAL}

El objeto de estudio de esta investigación es el discurso del editor de las revistas científicas, que se expresa en diferentes clases textuales, y que hemos agrupado aquí bajo el rótulo de "género editorial". En general, 
este discurso se materializa en textos, cuya autoría es de responsabilidad del editor o director de la revista. El artículo editorial de una publicación periódica históricamente ha tenido el objetivo de dar a conocer la opinión del editor o del grupo editorial, sobre aspectos que competen al ámbito temático en el que se inserta dicha publicación (González 2006). Normalmente se trata de un solo artículo por revista.

En relación con el contexto textual en el que aparecen, estos textos se ubican al comienzo de cada número de las revistas. La audiencia ideal de estos textos coincide con la audiencia a la cual las revistas científicas están destinadas, a saber, la comunidad de especialistas interesados en los contenidos de la revista. También en términos generales, se podría sostener que el género "editorial de revistas científicas" es un texto dependiente, en tanto, su razón de ser está relacionada con los otros textos que aparecen en ese medio.

En un estudio previo (Sabaj, Matsuda \& Fuentes, 2010), cuyo foco eran artículos de investigación, se determinó que los textos que aparecen en las revistas son muy variados, sobre todo en relación con las etiquetas (clases textuales) que utilizan los usuarios para denominarlos. En el estudio, se concluye que "mientras algunas revistas utilizan nombres específicos para los textos que presentan, otras revistas no siguen un criterio formal para la denominación de estos textos, utilizando una misma etiqueta para textos cuya función, estructura y contenido son variados" (Sabaj, Matsuda \& Fuentes, 2010: 145). Por esta razón, tal como ya hemos sostenido, cualquiera que desee hacer una descripción de los tipos textuales que aparecen en las revistas científicas, no se puede confiar de los nombres que a esos textos les asignan los usuarios.

\section{Metodología}

\subsection{Cómo identificar el propósito comunicativo de un género}

Tal como lo han descrito Sabaj, Matsuda y Fuentes (2010), definir el propósito comunicativo general de un género no es una tarea fácil. Esto porque, como ya hemos señalado, en ocasiones no existen marcas textuales para determinar esa función. Tampoco son de utilidad las denominaciones o etiquetas que reciben estos textos por parte de sus usuarios, ya que estas no 
necesariamente dan cuenta del género que se quiere definir (Sabaj, Matsuda \& Fuentes, 2010). Askehave y Swales (2001) proponen un procedimiento para la identificación de un género. Estos autores asumen que los géneros son dinámicos, y que pueden redefinirse según el propósito que los usuarios le van asignando de forma cambiante durante el tiempo. En cualquier caso, la determinación de la función textual, o propósito comunicativo, implica, por un lado, el análisis de las marcas textuales y, por otro, la consideración de los factores contextuales de la producción: el dispositivo, los participantes, los temas más frecuentes, entre otros.

Para comprender la forma en que se realizó el análisis, es necesario definir operativamente los siguientes términos: a) clase textual b) propósito comunicativo y c) tipo de texto. Una clase textual es la etiqueta que utilizan los usuarios para denominar los textos que usan. Como ya hemos sostenido, este nombre que le asignan los usuarios (en este caso, los editores), no es, por sí solo, un criterio confiable para determinar la función del texto que se quiere clasificar. Analizar una clase textual y determinar su propósito comunicativo, nos ha permitido asignarle un tipo de texto. Así, un tipo de texto se ha determinado en base al propósito comunicativo de un texto.

Para identificar los propósitos comunicativos de los editoriales de las revistas científicas, utilizamos un método basado en la teoría empíricamente fundada (Strauss \& Corbin, 1997). A partir de un análisis de 232 clases textuales en 29 revistas, se construyó un libro de códigos que se fue afinando en forma abductiva, esto es, contrastando las categorías con los datos, hasta que: a) los nombres de las categorías dieran cuenta lo más fielmente de los datos y, b) no aparecieran nuevas categorías. Tal como sostienen Sabaj, Matsuda y Fuentes (2010), este libro de códigos es una herramienta que permite, a partir de la aplicación de criterios formales, tipificar y comparar las clases textuales de las revistas contenidas en la Biblioteca electrónica Scielo. Cada criterio corresponde a la definición del propósito de un género o tipo de texto. En la siguiente tabla 1, se muestra un extracto del libro de códigos.

El extracto del libro de códigos muestra algunos propósitos comunicativos para determinar el tipo de texto al que corresponde distintas clases textuales de la Revista "Archivos de Medicina Veterinaria". Como podemos ver en las primeras tres filas, si bien la revista denomina con un mismo nombre a la clase textual, en rigor, se trata de géneros distintos, 
pues responden a propósitos comunicativos diferenciados. Por el contrario, también sucede que las revistas denominan con clases distintas (tal como se observa en las últimas tres filas), a textos que corresponden a un mismo género, en tanto poseen el mismo propósito comunicativo.

Tabla 1: Extracto del libro de códigos

\begin{tabular}{|c|c|c|c|}
\hline Revista & Clase & Propósito comunicativo & Tipo \\
\hline AMV & Editorial & $\begin{array}{l}\text { Se agradece a los evaluadores y } \\
\text { autores de la revista }\end{array}$ & Agradecimiento \\
\hline AMV & Editorial & $\begin{array}{l}\text { Se hace un comentario general } \\
\text { acerca de la disciplina, de la práctica } \\
\text { científica y/o políticas educacionales }\end{array}$ & Opiniones \\
\hline AMV & Editorial & $\begin{array}{l}\text { Se hace referencia a las características } \\
\text { o cambios de la revista }\end{array}$ & $\begin{array}{l}\text { Discurso de la revista sobre } \\
\text { la revista }\end{array}$ \\
\hline AMV & Presentación & $\begin{array}{l}\text { Se hace un comentario general acerca } \\
\text { de la disciplina }\end{array}$ & Opiniones \\
\hline AMV & Introducción & $\begin{array}{l}\text { Se hace un comentario general acerca } \\
\text { de la disciplina }\end{array}$ & Opiniones \\
\hline AMV & $\begin{array}{l}\text { Carta del } \\
\text { editor }\end{array}$ & $\begin{array}{l}\text { Se hace un comentario general acerca } \\
\text { de la disciplina }\end{array}$ & Opiniones \\
\hline
\end{tabular}

Para validar empíricamente el libro de códigos, se calculó la confiabilidad intercodificador (Fleiss, 1971), con los juicios de 8 evaluadores independientes sobre 391 observaciones, alcanzándose un acuerdo casi perfecto (Kappa $=0,92)$.

\subsection{La delimitación del corpus}

Para el análisis de los editoriales de las revistas científicas, se utilizaron los criterios de inclusión y exclusión, definidos en el Proyecto Fondecyt 11080097. En este proyecto, se utilizaron los siguientes criterios:

a) Se analizaron todas las revistas contenidas en la Base Scielo Chile, que publicaron números entre los años 2000 y 2008.

b) Sólo se analizaron aquellas clases textuales escritas en español. 
Para este estudio en particular, se agregó además el siguiente criterio:

c) Se consideraron todas las clases textuales que correspondían al discurso del editor, independientemente de la etiqueta (clase textual) con que fueran denominadas.

Para identificar estos textos, además de estos criterios, se tuvo en cuenta la posición en la cual aparecen en la revista, a saber, al inicio de cada número. Además, se constató que el discurso del editor solo aparece materializado en un solo texto por cada número.

A partir de la aplicación de estos criterios, el universo total de registros analizados corresponde a 14.460 textos de 72 revistas, agrupadas en 6 áreas de la ciencia. De estos textos, se determinó que un $10,7 \%$, esto es, 1.552 textos correspondían al discurso del editor. A estos 1.552 textos, se les aplicó el libro de códigos previamente validado, para identificar cuáles eran los propósitos comunicativos del discurso del editor de las revistas contenidas en la Base Scielo Chile. La relevancia de la base utilizada en este estudio, radica en su reconocimiento como una fuente oficial de la producción científica en nuestro país.

\section{Resultados y Discusión}

\subsection{Seis propósitos comunicativos de los artículos editoriales en las Revistas Scielo Chile}

En este apartado, mostramos los seis propósitos comunicativos del libro de códigos en los que se puede clasificar el discurso del editor de las revistas científicas (Tabla 2).

Tal como se aprecia en la Tabla 2, identificamos seis propósitos comunicativos de los artículos editoriales en las revistas científicas de la Base Scielo Chile. Cabe señalar que uno de estos propósitos presenta un grado menos específico de descripción. Se trata de un género (Discurso de la revista sobre la revista) en el que se agrupan subgéneros variados. Esta decisión se basa en el criterio de que si bien todos estos subgéneros tienen objetivos diferenciados, en conjunto, todos ellos hacen referencia al funcionamiento de la revista. 
Tabla 2: Seis propósitos comunicativos de los editoriales de las revistas científicas

\begin{tabular}{|l|l|}
\hline Tipo & Propósitos comunicativos \\
\hline Agradecimientos & Se agradece a los evaluadores y autores de la revista \\
\hline Opiniones & $\begin{array}{l}\text { Se hace un comentario general acerca de la disciplina, de } \\
\text { la práctica científica y/o políticas educacionales }\end{array}$ \\
\hline $\begin{array}{l}\text { Discurso de la revista sobre la } \\
\text { revista }\end{array}$ & $\begin{array}{l}\text { Se presentan 'Fe de erratas', se hace un discurso de } \\
\text { despedida y/o el editor rinde cuentas, se hace referencia } \\
\text { a los cambios en la revista, se convoca a los autores de la } \\
\text { revista, se presentan los evaluadores de la revista }\end{array}$ \\
\hline Homenajes & Se hace un homenaje a un miembro de la comunidad \\
\hline $\begin{array}{l}\text { Información sobre eventos de la } \\
\text { comunidad }\end{array}$ & $\begin{array}{l}\text { Se convoca a un evento o se hace una reseña de un evento } \\
\text { realizado. }\end{array}$ \\
\hline $\begin{array}{l}\text { Presentación de los artículos del } \\
\text { número de la revista }\end{array}$ & Se presentan los artículos contenidos en el número \\
\hline
\end{tabular}

\subsection{Variabilidad de las clases textuales asociadas a los propósitos comunicativos del discurso del editor}

Tal como hemos señalado, existe una gran variedad en las etiquetas que los usuarios (autores y editores) utilizan para denominar los tipos de textos que utilizan, definidos, estos últimos a partir de la determinación de su propósito comunicativo.

En la Tabla 3, se pueden encontrar los distintos nombres con que estos tipos de textos se denominan en las revistas.

Tal como queda en evidencia, los tipos de textos, definidos en este trabajo a partir de los propósitos comunicativos, aparecen denominados con nombres variados en las revistas científicas. Muchos de estos nombres son muy ambiguos, pues no aportan ninguna pista que dé cuenta del género que se está utilizando, por ejemplo, la denominación "documento". Por otra parte, se puede observar que los nombres de las clases textuales se utilizan en forma indistinta para identificar a géneros que tienen funciones diferenciadas. Por ejemplo, la etiqueta "editorial" puede ser utilizada para hacer referencia a textos que cumplen con las distintas funciones definidas. Existen otras etiquetas que son más transparentes, en tanto coincide el nombre de la clase textual con la función que el texto cumple. Es el caso de la etiqueta "agradecimiento", "opiniones", "convocatoria”, "homenaje”, "congresos" e "introducción”, las que, respectivamente, dan cuenta de manera más directa de las funciones definidas en este trabajo. 
Tabla 3: Variedad de las clases textuales asociadas a los propósitos comunicativos de los editoriales de las revistas científicas de Scielo Chile

\begin{tabular}{|l|l|}
\hline Tipos & Clases textuales \\
\hline Agradecimientos & Agradecimientos, Editorial, Documentos \\
\hline Opiniones & $\begin{array}{l}\text { Carta del editor, Colectánea, Editorial, En síntesis, } \\
\text { Comentario taxonómico, Documentos, Forum, } \\
\text { Introducción, Presentación, Special Document, } \\
\text { Jurisprudencia comentada, Opiniones, Palabras del editor. }\end{array}$ \\
\hline $\begin{array}{l}\text { Discurso de la revista sobre la } \\
\text { revista }\end{array}$ & $\begin{array}{l}\text { Editorial, Fe de erratas, Palabras del editor, Presentación, } \\
\text { Convocatoria, Listado de evaluadores. }\end{array}$ \\
\hline Homenajes & $\begin{array}{l}\text { Comentario, Conferencia, Documento, Editorial, Ensayos } \\
\text { ydocumentos, Homenaje, In memoriam, Opiniones, } \\
\text { Reseñas, Reseñas de fonogramas, Resumen de memoria. }\end{array}$ \\
\hline $\begin{array}{l}\text { Información sobre eventos de } \\
\text { la comunidad }\end{array}$ & $\begin{array}{l}\text { Special Document, Editorial, Opiniones, Simposio sobre } \\
\text { Economía espacial, Noticias, Congresos, Comentario, } \\
\text { Crónica, Carta del director, Ensayos y documentos, } \\
\text { Conferencias. }\end{array}$ \\
\hline $\begin{array}{l}\text { Presentaciones de los artículos } \\
\text { del número de la revista }\end{array}$ & $\begin{array}{l}\text { Editorial, Introducción, Preámbulo, Presentación, } \\
\text { Prólogo. }\end{array}$ \\
\hline
\end{tabular}

\subsection{Los editoriales de revistas cientificas: la variación de sus propósitos comunicativos a través de las áreas de la ciencia}

En la Tabla 4, se expone la frecuencia y el porcentaje de editoriales con respecto al total de registros en cada una de las áreas de la ciencia.

Tabla 4: Frecuencia de los editoriales y su representatividad porcentual a través de las áreas de la ciencia

\begin{tabular}{|l|c|c|c|}
\hline Área de la Ciencia & Registros & Editoriales & $\%$ \\
\hline Ciencias de la salud & 6.516 & 978 & 15,0 \\
\hline Ciencias de la tierra & 962 & 25 & 2,6 \\
\hline Ciencias de la vida & 1.036 & 59 & 5,7 \\
\hline Ciencias exactas & 681 & 39 & 5,7 \\
\hline Ciencias sociales & 3.845 & 251 & 6,5 \\
\hline Humanidades & 1.420 & 200 & 14,1 \\
\hline TOTALES & 14.460 & 1.552 & 10,7 \\
\hline
\end{tabular}


Tal como se observa en la Tabla 4, los editoriales representan un 10,7 $\%$ de todos los registros analizados. Las dos áreas de la ciencia donde este tipo de textos tienen una mayor presencia, respecto del total de lo que se produce en cada área, son las ciencias de la salud y las humanidades.

Por el contrario, en las ciencias de la tierra estos textos tienen una representatividad mínima con solo un 2,6\% del total de los textos que aparecen en las revistas de estas áreas. Con un porcentaje igual, las ciencias de la vida y las ciencias exactas $(5,7 \%)$, junto con las ciencias sociales que presentan un porcentaje levemente superior $(6,5 \%)$, constituyen el rango medio de aparición de este tipo de textos.

Si bien los porcentajes, por ser una medida normalizada, permiten que estos datos sean directamente comparables, se debe tener en cuenta que estos resultados pueden estar determinados por otras variables. Por ejemplo, por el porcentaje que cada área de la ciencia representa respecto del total de registros analizados; por el número de revistas incluidas en cada área de la ciencia; y por la cantidad de números que cada revista tiene en un año. Así por ejemplo, el alto porcentaje de los editoriales en las ciencias de la salud puede deberse a que: a) casi un 50\% de todo lo que se produce en Scielo Chile (y en casi todas las bases de datos científicas a nivel mundial) corresponde a estas áreas, b) las revistas de esta área tienen, en promedio, una cantidad mayor de números por año que los de cualquier otra área. Así entonces, la prevalencia de este tipo de textos en esta área estaría determinada por la mayor probabilidad que tienen estos textos de aparecer, dada la mayor cantidad de números de las revistas en estas áreas. Estos argumentos, sin embargo, no son transferibles al caso de las humanidades; esto, porque, tal como lo han reportado Sabaj, Matsuda y Fuentes (2010), las humanidades no superan en representatividad el $10 \%$ de todo lo que se produjo en Scielo durante el período analizado. Asimismo, en las humanidades el promedio de números por año no supera los 2 .

Con el fin de realizar un análisis comparativo, en la Tabla 5 se exponen a continuación los porcentajes de los propósitos comunicativos de los editoriales a través de las áreas de la ciencia. 
Tabla 5: Porcentaje de los propósitos comunicativos del discurso del editor a través de las áreas de la ciencia

\begin{tabular}{|l|c|c|c|c|c|c|}
\hline \multirow{2}{*}{ Áreas de la ciencia } & \multicolumn{7}{|c|}{ Propósitos comunicativos } \\
\cline { 2 - 7 } & AGR & O & DRR & H & IEC & P \\
\hline Ciencias de la salud & 0,61 & 46,63 & 15,13 & 9,61 & 25,77 & 2,25 \\
\hline Ciencias de la tierra & 0,00 & 8,00 & 24,00 & 40,00 & 24,00 & 4,00 \\
\hline Ciencias de la vida & 1,69 & 15,25 & 3,39 & 37,29 & 38,98 & 3,39 \\
\hline Ciencias exactas & 0,00 & 79,49 & 7,69 & 0,00 & 12,82 & 0,00 \\
\hline Ciencias sociales & 2,39 & 11,95 & 10,76 & 13,94 & 21,91 & 39,04 \\
\hline Humanidades & 1,00 & 5,00 & 8,50 & 45,50 & 30,50 & 9,50 \\
\hline TOTALES & 0,97 & 34,66 & 13,08 & 16,24 & 25,90 & 9,15 \\
\hline
\end{tabular}

Leyenda: AGR $\rightarrow$ Agradecimientos; O $\rightarrow$ Opiniones; DRR $\rightarrow$ Discurso de la revista sobre la revista; $\mathrm{H} \rightarrow$ Homenajes; IEC $\rightarrow$ Información sobre eventos de la comunidad; $\mathrm{P} \rightarrow$ Presentaciones

Para analizar y discutir los datos de la Tabla 5, comenzaremos por analizar la tendencia general (total), independiente de las áreas de la ciencia. Tal como se observa en los datos, el propósito comunicativo más importante de los editoriales de las revistas científicas es realizar un comentario de opinión. Tal como ya lo hemos mencionado (ver Tabla 2) se trata de un comentario general acerca de la disciplina, las prácticas científicas o las políticas educacionales. En estos casos, el editor adopta una posición respecto de los temas que son del interés de la comunidad discursiva que la revista representa. Es interesante destacar que esta función es coincidente con el propósito de los editoriales en otros contextos, a saber, en el caso de los editoriales de la prensa escrita (González, 2006), en tanto se trata de un texto donde se presenta la opinión de un editor sobre un tema. En el caso de los editoriales en contextos periodísticos, los temas son de interés público; en este caso en particular, en cambio, el factor distintivo está dado por los temas que son del interés particular de los destinatarios de la revista.

La segunda función más prominente de los editoriales de las revistas científicas, independiente del área de la ciencia, corresponde a la información sobre eventos científicos de la comunidad. Estos textos tienen un carácter netamente divulgativo, y sirven como un nexo entre los intereses de la revista y los de la comunidad en los que esa revista está inserta.

La tercera función más recurrente de los editoriales de las revistas científicas son los homenajes. Estos textos son relevantes, pues implican el reconocimiento de las autoridades epistémicas de una comunidad disciplinar. Al realizar estos 
homenajes, e identificar a las autoridades epistémicas de la comunidad, los editores definen, en cierta forma, cuáles son los supuestos epistemológicos, las líneas de investigación o los ejemplos a seguir en una disciplina en particular.

La cuarta función más importante de los editoriales de las revistas científicas corresponde, tal como ya lo hemos definido, a un género (Discurso de la revista sobre la revista), en el que se engloban subgéneros con propósitos diversos, cuyo elemento unificador es el hecho de que se refieren al funcionamiento de la revista. Los editores, a través de estos textos, regulan la interacción entre la revista y sus usuarios, principalmente, autores, evaluadores y lectores.

Las dos funciones menos frecuentes en términos porcentuales son, por un lado, las presentaciones y, por otro, los agradecimientos. Las presentaciones corresponden a un meta-texto, destinado principalmente a los lectores, en los que el editor se refiere a los artículos contenidos en el número de la revista. Se trata de textos de carácter descriptivo con algunos matices evaluativos. Por último los agradecimientos son una forma de reconocimiento que realizan los editores a los miembros que colaboran en el funcionamiento de la revista, específicamente, los destinatarios tienden a ser los evaluadores de la revista y, en menor medida, los autores.

Para realizar el análisis en detalle de los propósitos comunicativos de los editoriales por cada área de la ciencia, describiremos su variación basándonos en dos criterios: a) el número de funciones que se realizan en cada área y, b) la tendencia, en términos de los propósitos más y menos representativos en cada área de la ciencia. Estos datos aparecen sintetizados en la Tabla 6:

Tabla 6: Tendencias y número de propósitos comunicativos de los editoriales de las revistas científicas

\begin{tabular}{|l|c|c|}
\hline Áreas de la ciencia & Tendencias & Propósitos comunicativos \\
\hline Ciencias de la salud & O $>$ IEC $>$ H $>$ DRR $>$ P $>$ AGR & 6 \\
\hline Ciencias de la tierra & H $>$ DRR $=$ IEC $>$ O $>$ P & 6 \\
\hline Ciencias de la vida & IEC $>$ H $>$ O $>$ DRR $=$ P $>$ AGR & 3 \\
\hline Ciencias exactas & O $>$ IEC $>$ DRR & 6 \\
\hline Ciencias sociales & P $>$ IEC $>$ H $>$ O $>$ DRR $>$ AGR & 6 \\
\hline Humanidades & H $>$ IEC $>$ P $>$ DRR $>$ O $>$ AGR & 6 \\
\hline Tendencia General & O $>$ IEC $>$ H $>$ DRR $>$ P $>$ AGR & 6 \\
\hline
\end{tabular}

Leyenda: AGR $\rightarrow$ Agradecimientos; $\mathrm{O} \rightarrow$ Opiniones; DRR $\rightarrow$ Discurso de la revista sobre la revista; $\mathrm{H} \rightarrow$ Homenajes; IEC $\rightarrow$ Información sobre eventos de la comunidad; P $\rightarrow$ Presentaciones 
Tal como se muestra en la Tabla 6, en las ciencias de la salud, aparecen todas las funciones identificadas en el trabajo. En esta área, además, y solo en ella, la tendencia es igual a la tendencia general: lo que priman son las opiniones y lo menos relevante son los agradecimientos, siguiendo exactamente el mismo orden en ambos casos. Dados estos resultados, se podría establecer que en aquellas áreas donde priman los editoriales con la función de realizar un comentario de opinión, los editores buscan posicionar los temas relevantes o convertirse en referentes de los asuntos que interesan a la comunidad.

En el caso de las ciencias de la tierra, la función más importante son los homenajes y la menos importante las presentaciones. Cabe señalar que en esta área no aparecen los agradecimientos. Estos datos muestran que en esta área es relevante identificar y reconocer a las autoridades epistémicas del área, y que la relación con los usuarios (evaluadores y autores) no es una prioridad. A diferencia de las ciencias de la salud, en las ciencias de la tierra las opiniones no son un propósito comunicativo frecuente. Mucha más representatividad reciben, en este caso, los textos regulatorios, los que tienen por objetivo señalar aspectos relativos al funcionamiento de la revista, y los textos destinados a informar sobre eventos científicos.

En las ciencias de la vida, la tendencia muestra que el propósito comunicativo más típico de los editoriales es comunicar información sobre eventos científicos. Luego aparecen los homenajes y las opiniones. Este dato supone que el énfasis está puesto en la relación entre la revista y los miembros de la comunidad a la cual la revista está destinada.

Las ciencias exactas es el área donde menos propósitos comunicativos se encuentran: solo tres de los seis identificados. Si bien priman las opiniones, que como dijimos buscan posicionar a la revista como una voz de referencia en la comunidad, las otros propósitos en esta área son textos de vinculación con la comunidad (IEC) y el discurso de la revista sobre la revista, que como ya hemos establecido, son textos regulatorios que determinan el funcionamiento de la revista.

En las ciencias sociales, aparecen todos los propósitos identificados, siendo el más frecuente presentar los trabajos del número de la revista. Se trata de textos destinados a los lectores de la revista, donde se describen y evalúan los textos que aparecen en un número. En segundo y en tercer lugar aparecen la información sobre eventos científicos y los homenajes, 
respectivamente. Estos textos vinculan a la revista con la comunidad en la que se inserta. Relativamente, en esta área son menos importantes las opiniones. Este dato permite establecer que en estas áreas los editores no le dan tanta importancia al posicionamiento de la revista respecto de los temas relevantes de la comunidad. En los últimos lugares, aparece el discurso de la revista sobre la revista y los agradecimientos. Esto puede implicar, en primero término, que las revistas de esta área no regulan tanto la interacción con sus usuarios, en tanto estos textos se mantienen estables durante el tiempo. En segundo término, y esto es válido para todas las áreas de la ciencia, las revistas no acostumbran a agradecer el rol que cumplen los evaluadores y los autores en el funcionamiento de las revistas.

Por último, en las humanidades, el propósito comunicativo que más frecuentemente cumplen los editoriales de las revistas científicas es homenajear. Estos homenajes, junto a la información respecto de eventos científicos, apuntan a que en esta área de la ciencia se utiliza el editorial principalmente como un medio importante de reconocimiento de las autoridades de la comunidad discursiva y para funcionar como un medio de difusión de los eventos de la comunidad discursiva. El rol menos prominente de las opiniones en los editoriales de las revistas de humanidades sugiere que en esta área las revistas no buscan necesariamente posicionarse como referentes de opinión, sino más bien funcionar como medios de reconocimiento y difusión de eventos.

\section{Comentarios finales}

En este artículo, hemos descrito los propósitos comunicativos que cumplen los editoriales de las revistas científicas en seis áreas de la ciencia. Los resultados muestran que estos textos, que aparecen en casi todos los números (90\%), representan un 10,7\% de todo lo que se publica en las revistas. También hemos constatado que estos textos se etiquetan con nombres variados, algunos de los cuales son poco transparentes (como "documento"), en tanto no dan cuenta del propósito que estos textos cumplen en la comunidad discursiva.

Una de las principales conclusiones del trabajo realizado es que el género "editorial de las revistas científicas", entendido como el discurso del editor encargado de la revista, es multifuncional. En este sentido, y considerando 
la variedad de etiquetas que se utilizan para denominarlo, este género no es una entidad homogénea, sino que cumple con distintos propósitos comunicativos en la comunidad discursiva en la que circula.

De la clasificación de los propósitos comunicativos de los editoriales, hemos evidenciado que, independiente del área de ciencia, estos textos se utilizan principalmente para posicionar el discurso del editor respecto de los temas relevantes para la comunidad. Se podría establecer en esta línea, que el propósito comunicativo de los editoriales en las revistas científica adopta el propósito común que los editoriales tienen en el contexto periodístico, esto es, emitir una opinión, expresar un posicionamiento sobre un tema específico. La clasificación de los propósitos comunicativos de los editoriales en las revistas científicas, muestra además que la información sobre eventos científicos y los homenajes, son los otros dos propósitos comunicativos más importantes que cumple el género estudiado.

A partir del análisis comparativo de la representatividad porcentual y de los propósitos comunicativos de los editoriales de las revistas científicas en las distintas áreas de la ciencia, hemos podido establecer que existe un comportamiento muy variado.

Ahora bien, ¿qué implicancias tienen estos datos?, ¿qué reflejan respecto de la práctica científica?, ¿quiénes (y cómo) podrán sacarle algún provecho? En primer lugar, las razones que llevan a una revista a utilizar las editoriales con tal o cual propósito comunicativo de forma prominente en un área de la ciencia, son múltiples y su delimitación supera los objetivos de este trabajo. El uso efectivo de los editoriales con ciertos propósitos en ciertas áreas de la ciencia, sin embargo, permite avanzar en la comprensión de la forma en que socialmente se construye el conocimiento científico.

Los editoriales de las revistas científicas, en este sentido, son un medio privilegiado para entender las relaciones que se crean entre los miembros de una comunidad discursiva en particular. Estos textos reflejan la representación que cada comunidad tiene respecto de la producción y la difusión de la ciencia, en cada área específica, esto es, la forma en que, simbólica y estratégicamente, se comunican los miembros de una comunidad discursiva.

Así, los editoriales de las revistas científicas son un género que aporta nuevas luces respecto de la relación entre los actores más relevantes en el proceso de producción científica, a saber: los autores, los editores, los 
evaluadores y los lectores. Son justamente estos actores quienes podrán sacar mayor provecho de los datos de esta investigación. Entre estos actores, son los potenciales autores (los futuros generadores del conocimiento), quienes podrían aprovechar más concretamente este conocimiento.

Como profesores de la didáctica del discurso científico, sabemos que el desconocimiento de los autores sobre las prácticas en una comunidad discursiva es uno de los principales obstáculos que enfrenta un autor que pretende integrar su comunidad. Entre estos aspectos, comúnmente desconocidos para los escritores que recién se inician, se encuentran las revistas que existen en su área, y las características de los textos que se usan en su comunidad. Conocer los propósitos comunicativos de los editoriales puede ser para esos autores un espacio de exploración relevante.

Una limitación evidente de esta investigación es presentar, en dos niveles, categorías muy generales. Primero, sabemos que el propósito comunicativo denominado "discurso de la revista sobre la revista" agrupa elementos textuales muy heterogéneos. Por otro lado, la decisión de trabajar a nivel de las áreas de la ciencia, también puede ser criticable, en tanto bajo ese rótulo se encuentran disciplinas que sabemos son muy diversas. Independientemente de esta limitación, y tal como ya hemos defendido, los datos aportados en esta investigación permiten dar cuenta de dimensiones específicas de la producción de la ciencia, y que pueden ser de utilidad para todos los actores involucrados en este proceso.

Recebido em fevereiro de 2012 Aprovado em outubro de 2012 E-mails: omarsabaj@userena.cl cristian.gonzalez@ucv.cl

\section{REFERENCIAS BIBLIOGRÁFICAS}

Askehave, Inger \& Swales, John. 2001. Genre identification and communicative purpose: A problem and a possible solution. Applied Linguistics, $22(2), 95-212$.

B Hatia, Vijay. 1993. Analysing genre: Language use in professional settings. London: Longman.

1997. Genre-Mixing in academic introductions. English for Specific Purposes, 16 (3), 181-195. 
. 2002. A generic view of academic discourse. En J. Flowerdew (Ed.), Academic discourse (pp. 21-39). Cambridge: Cambridge University Press.

. 2004. Worlds of written discourse. A genre based view. Sydney: Continuum.

Brinker, Kalus. 1988. Linguistische Textanalyse. Eine Einfübrung in Grundbegriffe und Methoden. Berlin : Erich Schmid.

Charaudeau, Patrick. 2006. El contrato de comunicación en una perspectiva lingüística. Opción 22 (49), 38-54.

Ciapuscio, Guiomar. 1994. Tipos textuales. Buenos Aires: Eudeba.

Ciapuscio, Guiomar. 2005. La noción de género en la Lingüística Sistémico Funcional y en la Lingüística Textual. Revista Signos. Estudios de Lingüística 38 (57), 31-48.

Dudley-Evans, Anthony. 1994. Genre analysis: an approach for text analysis for ESP. In M. Coulthard (ed.) Advances in Written Text Analysis (pp. 219-228). London: Routledge.

FLEISS, Joseph. 1971. Measuring nominal scale agreement among many raters. Psychological Bulletin 76 (5): 378-382.

GonzÁlez, Cristian. 2006. Los sujetos participantes en los editoriales de la prensa escrita chilena. Revista Signos. Estudios de Lingüística 39 (61), 181-203.

Sabaj, Omar; Matsuda, Ken \& Fuentes, Miguel. 2010. Un Modelo para la Homogeneización de las Clases Textuales de la Biblioteca Electrónica Scielo-Chile: la Variabilidad del Artículo de Investigación en Diversas Disciplinas. Información Tecnológica 21 (6), 133-148.

Strauss, Anselm \& Corbin, Juliete. 1997. (Eds.). Grounded Theory in Practice. London: Sage.

SwALES, John. 1990. Genre analysis: English in academic and research settings. Cambridge: Cambridge University Press.

SwALES, John. 2004. Research genres: Explorations and applications. Cambridge: Cambridge University Press.

Valderrama, José. 2001. La publicación en revistas especializadas, un recurso estratégico en la investigación científica y tecnológica. En A. Cellino (Ed.), Los laberintos del futuro. Ciencia y tecnología en América Latina (pp. 91-123). Santa Fe: Editorial de la Universidad Nacional del Litoral.

van Dijk, Teun. 1978. Tekstwetenschap. Een interdisciplinaire inleiding. Amsterdam: Het Spectrum. 